\title{
Reducing Surface Subsidence Risk Using Solid Waste Backfill Technique: a Case Study under Buildings
}

\author{
Meng Li*, Jixiong Zhang*, Kai Sun, Zhongya Wu, Nan Zhou \\ State Key Laboratory of Coal Resources and Safe Mining, School of Mines, \\ China University of Mining and Technology, Xuzhou, Jiangsu, China
}

Received: 1 July 2018

Accepted: 3 September 2018

\begin{abstract}
Coal mining-induced surface subsidence causes many environmental problems and geological hazards, including damage to buildings, depletion of water resources, and land desertification. However, numerous coal resources in China are buried under buildings. To solve these problems, a solid waste backfill mining (SWBM) technique has been proposed to control the surface subsidence under buildings. This paper introduced the fundamental principle of the SWBM technique and then presented a model based on the theory of equivalent mining height (EMH) to predict surface subsidence. In addition, the compaction effects of backfill materials were obtained through an experiment on the compaction properties thereof. Afterward, measuring transects were arranged to conduct field observation of surface subsidence: when the backfill materials are sufficiently compacted, the compression degree is 0.13 with $13 \%$ deformation. Moreover, the measured maximum subsidence was $18 \mathrm{~mm}$, which is lower than that predicted for the maximum deformation of a nearby building. In addition, surface buildings were slightly influenced by coal mining and no obvious cracks were found. Therefore, this technique provides a new approach for controlling the surface subsidence induced by coal mining.
\end{abstract}

Keywords: solid waste, surface subsidence, backfill mining, environmental protection, risk prevention

\section{Introduction}

In China, as the caving method is mainly adopted to dispose of goafs, violent strata movement and largescale surface subsidence are inevitable [1-3], which causes various problems such as: damage to buildings, village relocation, depletion of water resources, land desertification, etc. [4-5]. Large-scale extraction of coal

*e-mail: zjxiong@cumt.edu.cn seams alters the distribution of energy, which contains both stress and displacement of the surrounding rock mass [6-7]. The downward movement of roof strata extends upwards, resulting in the subsidence of the ground. According to statistics, every year the subsiding areas induced by coal mining based on the caving method amount to about $40,000 \mathrm{hm}^{2}$ and the financial losses caused are about 2 billion RMB/a. At present, in China the total area of coal mining-induced surface subsidence has reached $700,000 \mathrm{hm}^{2}$. Additionally, "three unders" (under buildings, under railways, and 
under water bodies) unexploited coal amounts to 13.79 billion tons, of which that under buildings accounts for about 9.468 billion tons, accounting for $69 \%$ of the total unexploited coal and involving 2,030 villages in mining areas [8-9]. Furthermore, in the process of coal mining, a large amount of solid waste is produced and accumulated on the ground, taking up myriad land resources and polluting the environment [10-11]. In recent years, with the intensification and deepening of coal mining works, the consequent environmental problems [12-13] have become increasingly serious, including surface subsidence, the accumulation of solid waste, etc., especially for those mines with significant amounts of "three unders" coal mining issues. Therefore, it has become a research focus for those seeking to develop an effective technique for controlling surface subsidence while simultaneously disposing of the resulting solid waste. Under this background, some techniques such as paste backfill [14-15], grout injection into the overburden [16-18], and SWBM [19-21] techniques have been proposed to solve the above problems. Compared with paste backfill and grout injection into the overburden, solid waste backfill can achieve in-situ backfilling of underground gangue, which does not need to lift gangue to the ground, the entire filling material preparation process is in the underground mine. The solid waste material preparation is relatively simple and no solidification is required after backfill; besides, the backfill and mining processes are highly coordinated and mechanized.

The solid waste backfill mining (SWBM) technique is developed on the basis of fully mechanized coal mining. It is designed to control strata movement and surface subsidence by conveying solid waste using a vertical feeding system to shafts [22], where the solid waste is crushed and then filled into the goaf of the working face to support overlying strata. Owing to this technique using backfill materials to fill the goaf, it produces different strata movement and surface subsidence profiles than those found when using the caving method [23-24]. Therefore, the effect of controlling surface subsidence through this technique needs to be researched. Taking Tangshan mine in Hebei, China, for instance, this paper introduced the fundamental principle of the SWBM technique, predicted the surface subsidence after backfill mining, and tested the compaction effect to analyze the control effect on surface subsidence. By doing so, this research attempts to provide a new method for controlling the surface subsidence induced by similar causes such as coal mining.

\section{Study Site}

Tangshan mine was established in 1878 and is one of the larger mines to have first used mechanized coal mining. As the coal resources in coal mines are exploited, mine reserves gradually decline. In addition,
Tangshan mine is situated under downtown Tangshan, so a large amount of coal, 171.173 million tons in total, is under buildings, of which the amount of the coal under buildings in $T_{3}$ and $T_{4}$ regions is up to 49.2 million tons. The large amounts of coal under buildings have restricted the survival and development of the coal mine.

At present, three quarters of the coal resources under buildings are exploited through population relocation, which leads to serious ecological destruction and high costs. To solve the aforementioned problems, the SWBM technique has been adopted in coal mining to protect surface buildings from the influence of coal mining. This study selected the $\mathrm{T}_{3}$ region as an experimental mining area where the coal-bearing areas cover about $2 \mathrm{~km}^{2}$ and the affected mining areas are predicted to cover $6 \mathrm{~km}^{2}$. Surface buildings in this experimental area are mainly brick or brick-wood structured bungalows built after Tangshan earthquake, including companies, factories, wholesale and retail outlets, and dense residential zones (Fig. 1). According to the (as yet) incomplete statistics available, there are about 800 enterprises and public institutions covering areas of $1,800,000 \mathrm{~m}^{2}$ inhabited by a population of around 90,000 .

Given the mining regulations for exploiting the coal under buildings and the density of buildings above the working faces [25], the maximum fortification indices for the displacement and deformation of the ground were determined. Hence, the maximum subsidence is expected to be smaller than $500 \mathrm{~mm}$, and the maximum values of horizontal compressive and stretching deformations need to be larger than $-2 \mathrm{~mm} / \mathrm{m}$ and smaller than $1.5 \mathrm{~mm} / \mathrm{m}$, respectively. Additionally, the maximum curvature and inclination are supposed to be smaller than $0.2 \mathrm{~mm} / \mathrm{m}^{2}$ and $2 \mathrm{~mm} / \mathrm{m}$, respectively.

The SWBM technique was first applied to working face $\mathrm{T}_{3} 281 \mathrm{~N}$, where the recoverable reserves are 217,600 tons, the average dip angle of the coal seam is $8.5^{\circ}$, and the length of the working face and the advance length are $120 \mathrm{~m}$ and $350 \mathrm{~m}$, respectively. In addition, with an average mining height of $3.7 \mathrm{~m}$, the working face lies at an elevation of 690 to $731 \mathrm{~m}$ below sea level, while the ground is $16 \mathrm{~m}$ above sea level. In the coal preparation plant attached to Tangshan mine, around 800,000 tons of gangues are produced every year, which are stockpiled on the ground surface. To protect the environment and dispose of these gangues in the meantime, these gangues were crushed to serve as backfill materials.

\section{SWBM Technique}

\section{Fundamental Principle}

The SWBM technique, developed based from the fully mechanized coal mining method, can realize coal mining and backfilling at the same time under the cover of a backfill support. Compared with fully mechanized 


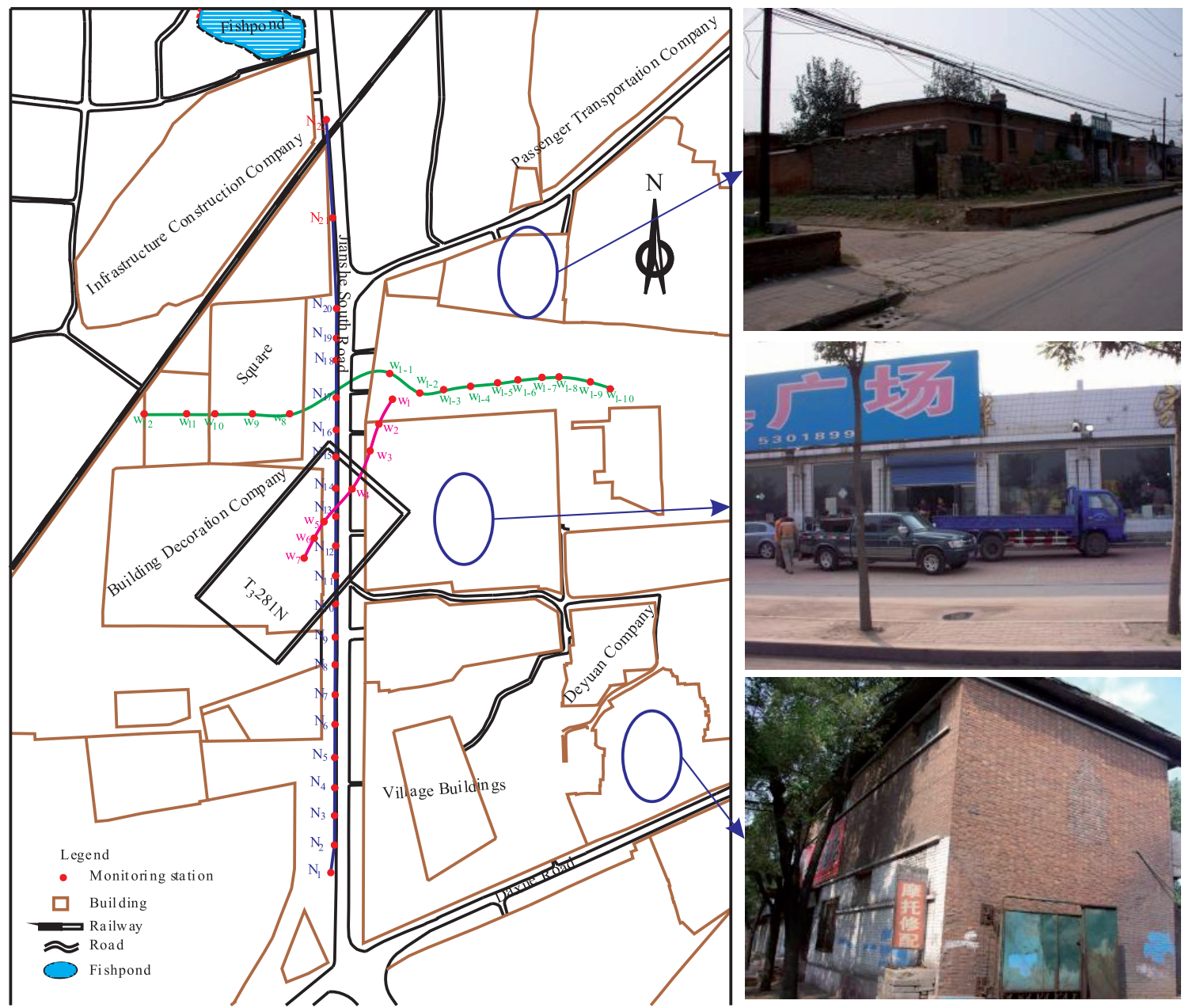

Fig. 1. Distribution of surface building and layout of the monitoring stations.

coal mining, SWBM has the same coal mining system but uses a vertical feeding system that can safely and efficiently convey solid waste to the goaf in the working face, and a compaction system behind the backfill support, as illustrated in Fig. 2.
The fundamental principle of the SWBM technique is to convey solid waste such as gangues, construction waste, coal ash, and mineral waste residues to a storage bin in the shaft by using a vertical feeding system. Then, through an underground transportation system,
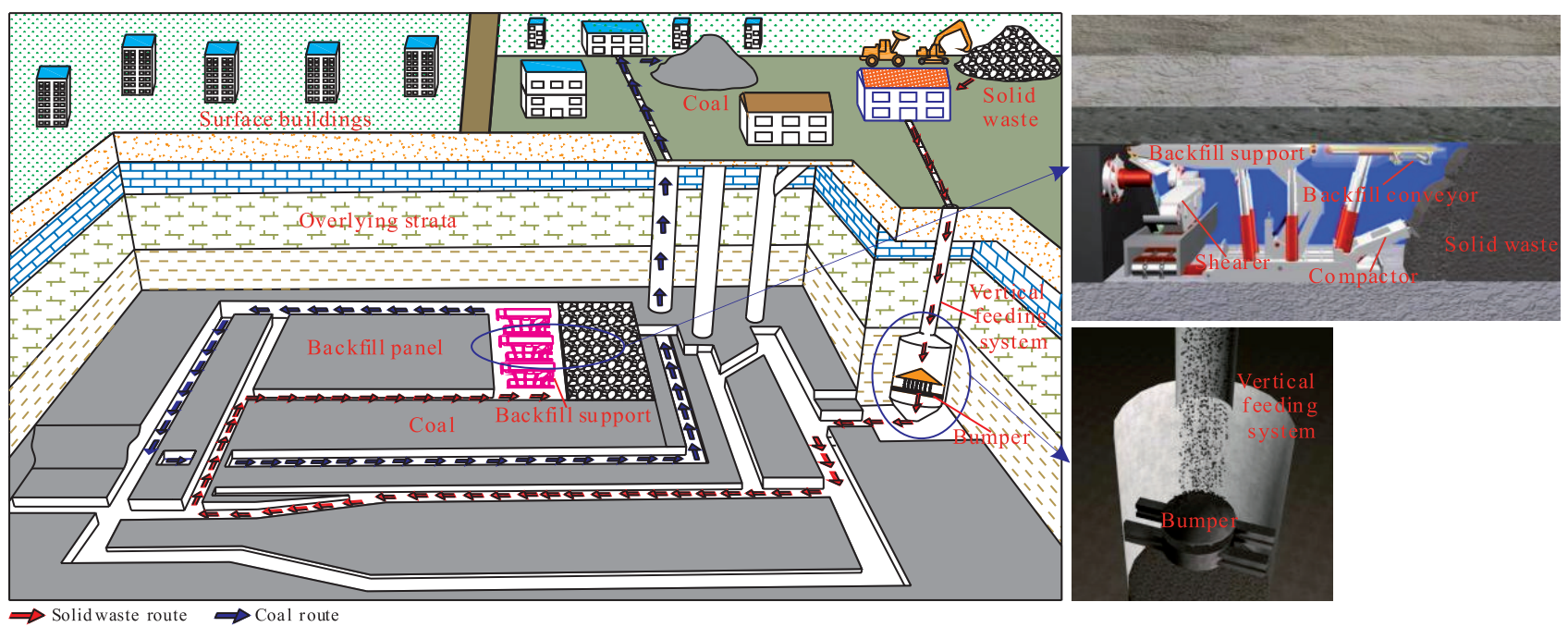

Fig. 2. Fundamental principle of the SWBM technique. 


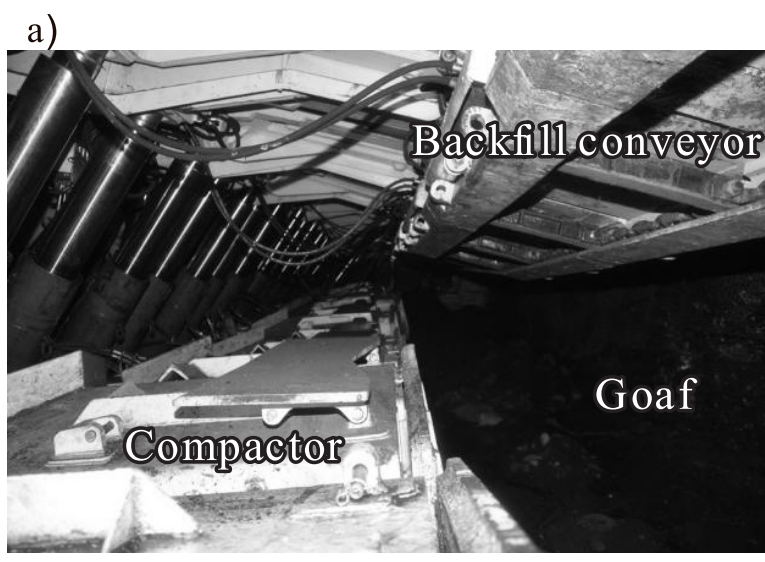

b)

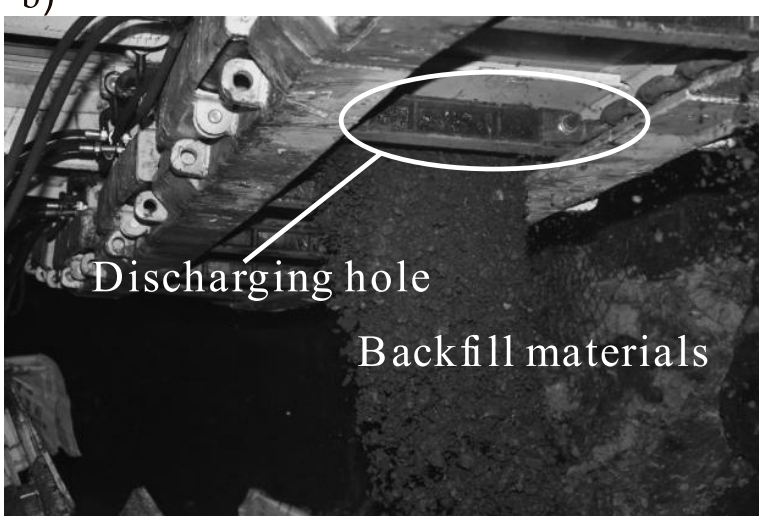

c)

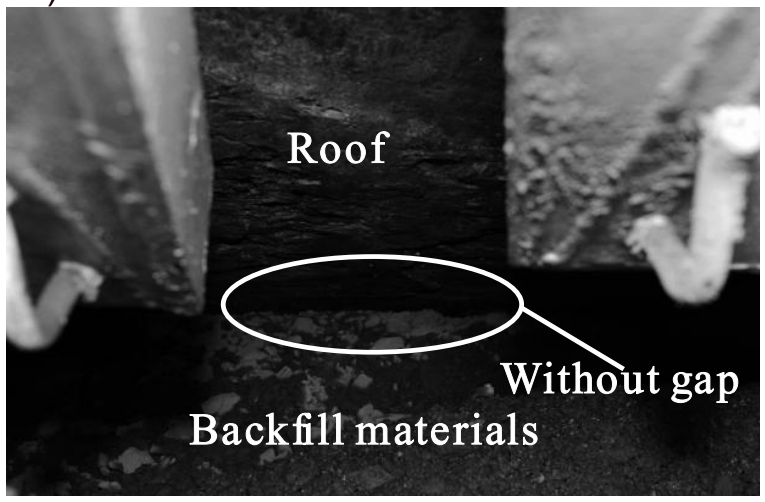

Fig. 3. a) Backfill support, b) Backfill conveyor, c) No gap with roof.

a)

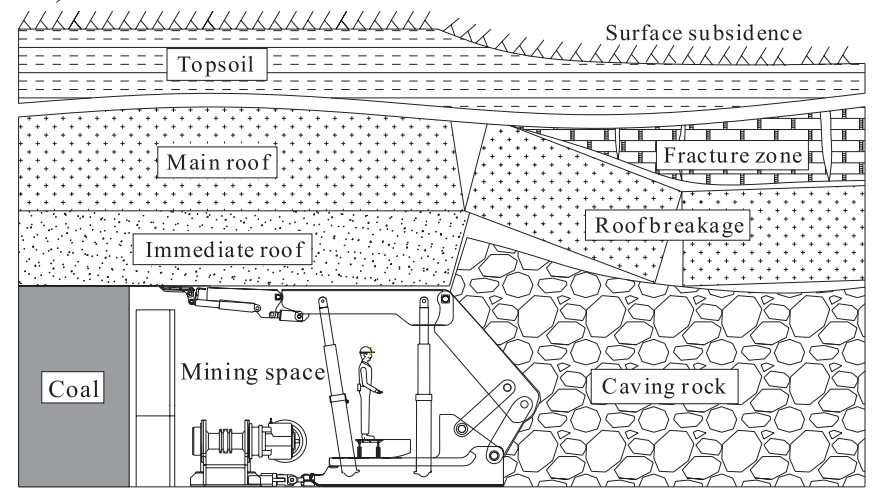

the backfill materials in the storage bin are transported to a backfill conveyor hanging in the back top beam of the backfill support (Fig. 3a). Afterward, the backfill materials are poured into the goaf through a discharging hole in the backfill conveyor (Fig. 3b), and then compacted by a compactor until they make contact with the roof, leaving no gap (Fig. 3c).

\section{Characteristics of Strata Movement and Surface Subsidence}

For traditional fully mechanized coal mining, with the advance of the working face, the roof caves and breaks under the load of the overlying strata, and then the caving and breakage extend to the overlying strata, generating caving, fracture, and bending zones, which forms a large-scale subsidence basin (Fig. 4a), while in SWBM, as the working face advanced, backfill materials filled the goaf and then made contact with the roof. In this case, the overlying strata mainly bend and subside with fractures only appearing in local areas and no caving zone is found, which validates the idea that the SWBM technique is effective in controlling surface subsidence (Fig. 4b).

According to the patterns of coal mining-induced subsidence, the subsidence is directly related to mining height, that is the lower the mining height, the smaller the surface subsidence and vice versa. As filling backfill materials into goaf reduces mining height, surface subsidence is controlled and surface buildings are prevented from being damaged.

As to the SWBM technique, the key to decreasing overlying strata movement and surface subsidence is to control the effective thickness of the backfill materials after being compacted under the load of the overlying strata. After being filled into goaf, the backfill materials serve as the main support and bear most of the load imposed by the overlying strata so they are compacted [26-27], which is equivalent to lowering the mining height. Therefore, an equivalent mining height (EMH) theory [23] was presented to study the pattern of SWBM-induced surface subsidence. Here, the EMH is

b)

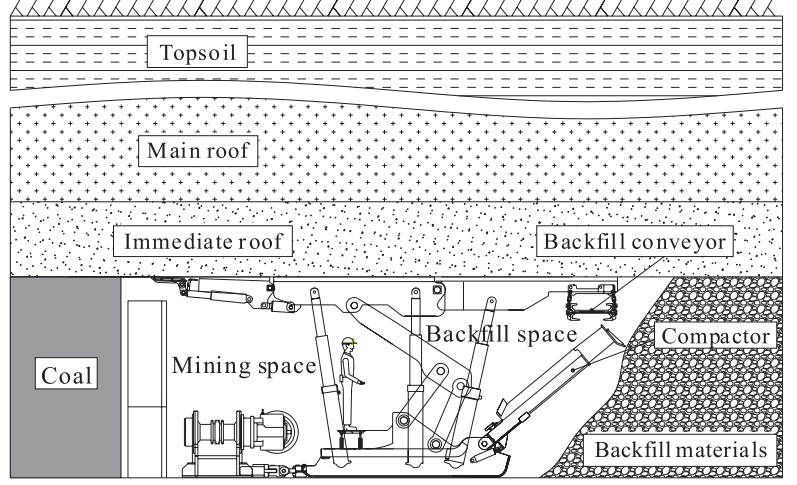

Fig. 4. a) Caving mining method, b) SWBM. 
a)

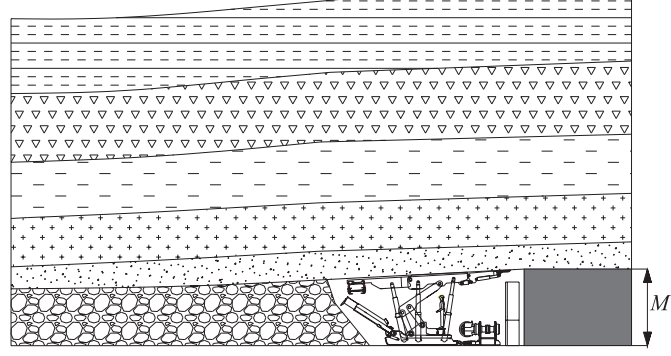

b)

c)

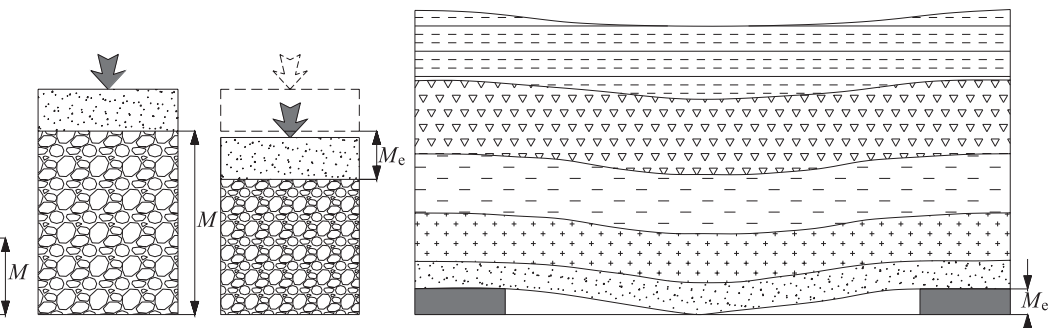

Fig. 5. a) backfill mining (mining height $M$ ), b) roof subsidence $M_{\mathrm{e}}$, c) caving mining (mining height $M_{\mathrm{e}}$ ).

defined as the height obtained by subtracting the height of the compacted backfill materials from the actual mining height of the backfill mining face.

Suppose that the effects of strata movement and surface subsidence caused by using the SWBM technique and the caving method are the same when the thicknesses of the mined coal seams are $\mathrm{M}$ and $\mathrm{Me}$, respectively, where Me is taken as the EMH (see Fig. 5) and may be calculated thus:

$$
M_{\mathrm{e}}=h_{\mathrm{t}}+(1-h)\left(M-h_{\mathrm{t}}\right)
$$

...where $M$ is actual mining height and $M_{e}$ represents EMH. Besides, $\eta$ denotes the degree of compaction of the backfill materials and $h_{t}$ is the early subsidence in the roof.

The degree of compaction refers to the degree of compaction of the backfill materials under the load from the overlying strata and is also defined as the ratio of the height after compaction to the original height of the backfill materials. It can be obtained through a mechanical test for the compaction of the backfill materials, and the early subsidence amount of the roof can be obtained through field observation.

\section{Prediction of Surface Subsidence Based on EMH Theory}

\section{Characteristics of Strata Movement}

The probability integral method was proposed by Liu and Liao [28], a Chinese scholar, from the stochastic medium theory put forward by Polish scholar Litwiniszyn [29]. The prediction parameters of this method mainly include subsidence factor, horizontal movement factor, tangent value of main influence angle, deviation of the inflection point, and the propagation angle for mining influence. Nowadays, the probability integral method has been developed quite well and has become one of the most commonly used methods to predict surface subsidence. Therefore, this method is adopted in this paper to predict surface subsidence. The prediction parameters in the caving method cannot be used directly in this method: they need to be corrected according to the patterns of the SWBM-induced surface subsidence and strata movement. Hence, the mining height can be calculated based on EMH theory.

In this model, the surface movement and deformation can be computed according to Eq. (2):

$$
\begin{aligned}
& W(x)=\frac{W_{0}}{2}\left[\operatorname{erf}\left(\frac{\sqrt{\pi}}{r} x\right)+1\right] \\
& i(x)=\frac{\mathrm{d} W(x)}{\mathrm{d} x}=\frac{W_{0}}{\mathrm{r}} e^{-\pi \frac{x^{2}}{\mathrm{r}^{2}}} \\
& k(x)=\frac{\mathrm{d}^{2} W(x)}{\mathrm{d}^{2} x}=-2 \pi \frac{W_{0}}{\mathrm{r}^{3}} x e^{-\pi \frac{x^{2}}{\mathrm{r}^{2}}} \\
& U(x)=\operatorname{bri}(x)=\mathrm{b} W_{0} e^{-\frac{\pi x^{2}}{\mathrm{r}^{2}}} \\
& \mathcal{E}(x)=\operatorname{brk}(x)=-2 \pi \mathrm{b} \frac{W_{0}}{\mathrm{r}^{2}} x e^{-\pi \frac{x^{2}}{\mathrm{r}^{2}}}
\end{aligned}
$$

...where $W_{0}=$ Meqcos $\alpha$ and $r=H / \operatorname{tg} \beta, W_{0}$ is the maximum subsidence and $r$ represents the main influence radius, $M_{e}$ and $q$ are the EMH, and surface subsidence factor, respectively. In addition, $b$ is the horizontal movement factor, $\operatorname{tg} \beta$ refers to the tangent value of the main influence angle and $\alpha$ denotes the dip angle of a coal seam.

The formulae for computing the maximum values of surface movement and deformation induced by SWBM are:

$$
\begin{aligned}
& i_{0}=W_{0} / r \\
& k_{0}= \pm 1.52 \frac{W_{0}}{r^{2}} \\
& U_{0}=b W_{0} \\
& \varepsilon_{0}= \pm 1.52 b W_{0} / r
\end{aligned}
$$

...where $i_{0}$ and $k_{0}$ are the maximum inclination and curvature, respectively. Moreover, $U_{0}$ and $\varepsilon_{0}$ are the maximum values of horizontal movement and deformation, respectively. 
Table 1. Prediction parameters for SWBM-induced surface subsidence.

\begin{tabular}{|c|c|c|c|c|c|}
\hline Parameter & $\begin{array}{c}\text { Subsidence } \\
\text { factor }\end{array}$ & $\begin{array}{c}\text { Tangent value of the } \\
\text { main influence angle }\end{array}$ & $\begin{array}{c}\text { Deviation of the } \\
\text { inflection point }\end{array}$ & $\begin{array}{c}\text { Horizontal movement } \\
\text { factor }\end{array}$ & $\begin{array}{c}\text { Propagation angle of mining } \\
\text { influence }\end{array}$ \\
\hline Caving method & $q$ & $\operatorname{tg} \beta$ & $S$ & $b$ & $\theta_{0}$ \\
\hline SWBM technique & $1.05 q$ & $\operatorname{tg} \beta-0.2 \sim 0.3$ & $S+0.05 \sim 0.1 H$ & $\approx b$ & $\approx \theta_{0}$ \\
\hline
\end{tabular}

\section{Determining the Prediction Parameters}

After the EMH in the SWBM is obtained, to ensure accuracy in any prediction of surface subsidence, the relevant parameters in the probability function model need to be determined. As is known, strata movement and surface subsidence caused by SWBM differ from those induced by the caving method; they extend upward with the compaction of the backfill materials, thus greatly reducing surface subsidence. Therefore, the parameters of the EMH-based probability function model cannot be directly selected according to those of the probability integral method based on the similar mining height in the mining of thin seams, but require correction. By making the most of the existing observation results of surface subsidence, the quantitative relationships between the prediction parameters of the SWBM-induced surface subsidence and the caving method was established by using a theoretical method. The determined prediction parameters of the SWBM-induced surface subsidence are listed in Table 1.

\section{Effects of Controlling Surface Subsidence}

\section{Compaction Effects on the Backfill Materials}

The samples taken from the $\mathrm{T}_{3} 281 \mathrm{~N}$ working face were used to test the compaction properties of the backfill materials and the maximum particle diameter of the samples was shown to be $50 \mathrm{~mm}$, because this range of particle size has strong deformation resistance. During compression, the large particles form a skeleton structure and the smaller particles fill the voids, thereby improving the rigidity. In addition, the larger particle size range helps to reduce gangue-crushing work during the preparation process of solid backfill mining materials, as proven by some research. The experimental testing system included an electro-hydraulic servo compression testing machine and a compaction device. In addition, with a maximum axial force of $5,000 \mathrm{kN}$, the testing machine is equipped with data acquisition software that can obtain mechanical parameters such as load and displacement. Besides, the compaction device is a self-designed steel cylinder of $305 \mathrm{~mm}$ high with the inside and the outside radiuses being 125 and $137 \mathrm{~mm}$, respectively. The load is applied by the testing machine through a loading plate in the compaction device. The radius and height of this loading plate are $124 \mathrm{~mm}$ and $40 \mathrm{~mm}$, respectively. The experimental procedure was as follows:
1. Place the samples in the compactor

Some samples were weighed and then put into the compaction device in layers, followed by the smoothing of the sample surface.

2. Compute the original filling height of the samples before loading

When the samples were put into the compaction device, the loading plate was put on the upper surface of the samples. The heights of the steel cylinder and the dowel steel and the thickness of the loading plate were $H_{1}(305 \mathrm{~mm}), H_{2}(100 \mathrm{~mm})$, and $H_{3}(40 \mathrm{~mm})$, respectively. Furthermore, the dowel steel exceeded the steel cylinder height, which is denoted as $\mathrm{H}_{4}$. According to the above data, the original filling height can be calculated from: $H_{0}=H_{1}+H_{4}-H_{2}-H_{3}$, as shown in Fig. 6 .

3. Applying axial load to the samples

The compaction device was put into an electrohydraulic servo compression-testing machine to load it until the virgin stress was reached. The displacement and loading during compaction were recorded.

The relationship between the degree of compaction and the stress during the compaction for the backfill materials is illustrated in Fig. 7; the degree of compaction for the backfill materials decreased gradually and tended to a stable state. When the stress was $18 \mathrm{MPa}$, matching the virgin stress, the degree of compaction was 0.87 , which indicated that only $13 \%$ deformation of the backfill materials was generated in the compaction process. Besides, the average early subsidence of the

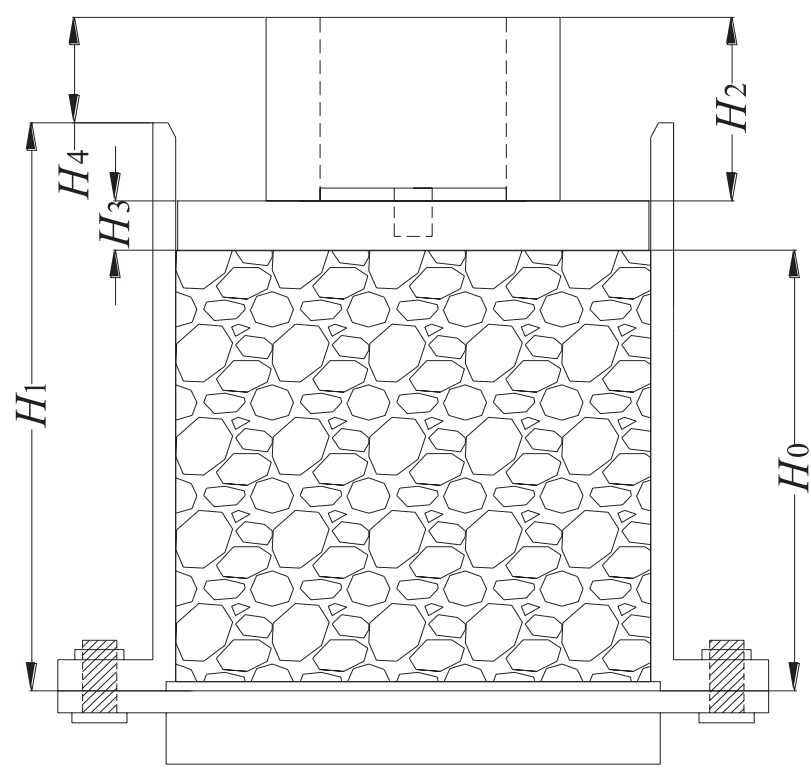

Fig. 6. Original filling height. 


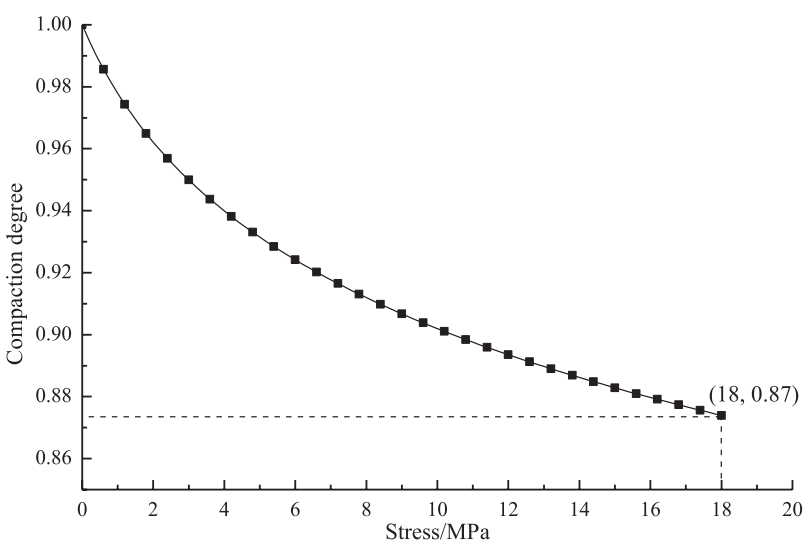

Fig. 7. Relationship between degree of compaction and stress.

floor was measured as being $75 \mathrm{~mm}$ and the EMH was computed to be $0.544 \mathrm{~m}$, according to Eq. (1).

\section{Predicting Surface Subsidence}

According to the EMH obtained and the parameters for surface movement caused by coal mining using the caving method, the prediction parameters for the surface subsidence of the $\mathrm{T}_{3} 281 \mathrm{~N}$ backfill working face were determined, as listed in Table 2.

Applying the method for predicting surface subsidence based on the EMH theory, the SWBM induced surface movement and deformation in the $\mathrm{T}_{3} 281 \mathrm{~N}$ working face were predicted. Table 3 shows the maximum surface movement and deformation after mining the $\mathrm{T}_{3} 281 \mathrm{~N}$ working face using the SWBM technique. According to the table, the curvature was less than $0.01 \mathrm{~mm} / \mathrm{m}^{2}$ and the maximum subsidence and stretching deformation were $258 \mathrm{~mm}$ and $0.46 \mathrm{~mm} / \mathrm{m}$, respectively. In addition, the minimum compression deformation was $-0.87 \mathrm{~mm} / \mathrm{m}$. All of these predicted values were much smaller than the critical values for damaging buildings.

\section{Field Measurements}

According to the actual situation of the $\mathrm{T}_{3} 281 \mathrm{~N}$ backfill face and the pattern of mining subsidence, as a)

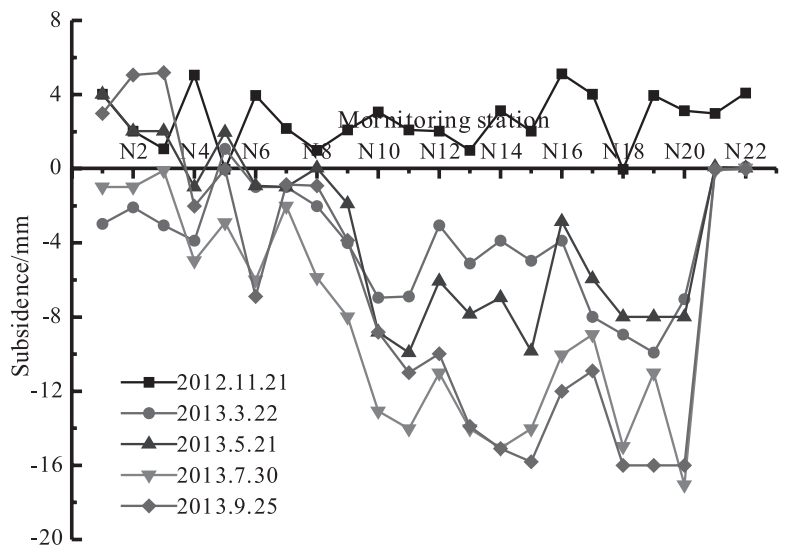

b)

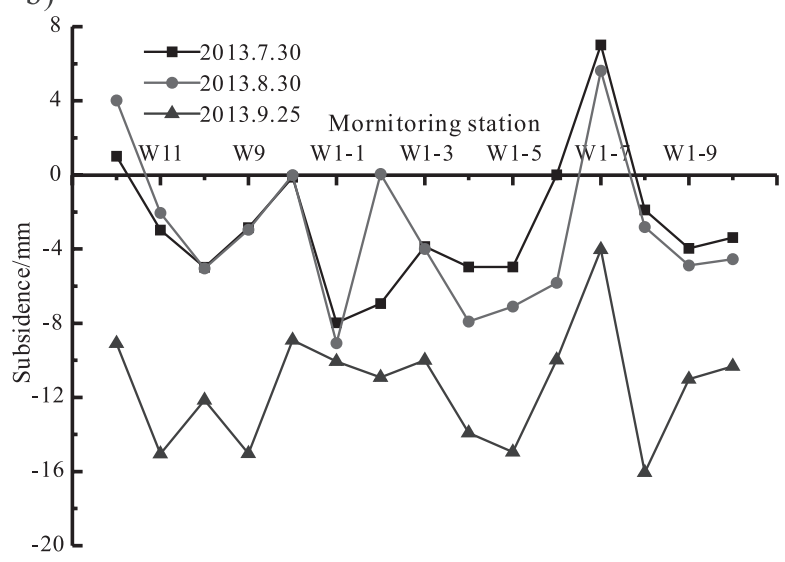

c)

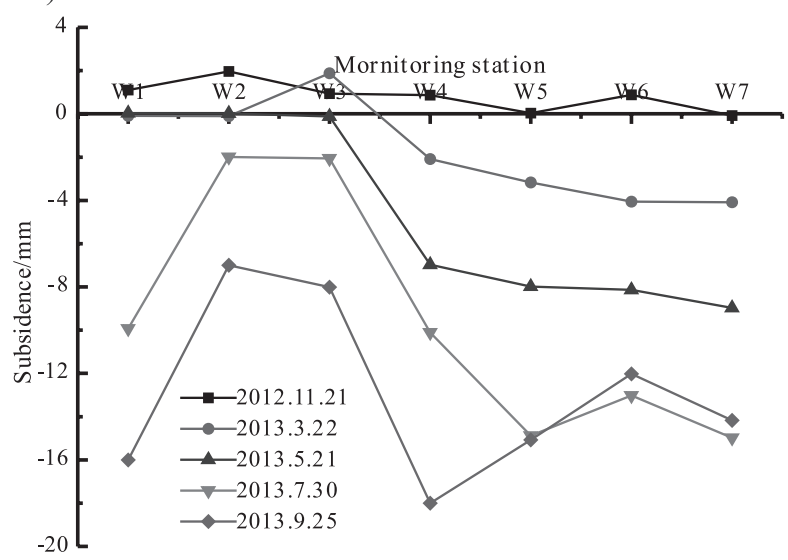

Fig. 8. a) NS direction, b) EW direction, c) Advance direction.

Table 2. Prediction parameters for the surface subsidence in $\mathrm{T}_{3} 281 \mathrm{~N}$ backfill face.

\begin{tabular}{|c|c|c|c|c|c|}
\hline Parameter & $\begin{array}{c}\text { Subsidence } \\
\text { factor }\end{array}$ & $\begin{array}{c}\text { Horizontal movement } \\
\text { factor }\end{array}$ & $\begin{array}{c}\text { Tangent value of the } \\
\text { main influence angle }\end{array}$ & $\begin{array}{c}\text { Propagation angle of } \\
\text { mining influence }\end{array}$ & $\begin{array}{c}\text { Deviation of the inflection } \\
\text { point }\end{array}$ \\
\hline Values & 0.74 & 0.37 & 1.8 & 85 & 12 \\
\hline
\end{tabular}

Table 3. Maximum surface movement and deformation induced by mining the $\mathrm{T}_{3} 281 \mathrm{~N}$ backfill face.

\begin{tabular}{|c|c|c|c|c|c|c|}
\hline \multirow{2}{*}{ Subsidence $(\mathrm{mm})$} & \multicolumn{2}{|c|}{ Horizontal movement $(\mathrm{mm})$} & Horizontal deformation $(\mathrm{mm} / \mathrm{m})$ & \multicolumn{3}{c|}{ Inclination $(\mathrm{mm} / \mathrm{m})$} \\
\cline { 2 - 8 } & NS direction & EW direction & NS direction & EW direction & NS direction & EW direction \\
\hline 258 & -121 & -67 & $-0.87,0.46$ & $-0.54,0.42$ & -0.78 & -0.52 \\
\hline
\end{tabular}


well as the geographical features of the working face, three survey lines were arranged in three directions, including NS, EW, and the advance direction of the working face to observe the surface subsidence. Monitoring stations $\mathrm{N}_{1}-\mathrm{N}_{22}, \mathrm{~W}_{8}-\mathrm{W}_{12}, \mathrm{~W}_{1-1}-\mathrm{W}_{1-10}$, and $\mathrm{W}_{1}-\mathrm{W}_{7}$ were set on the survey lines in the three directions with their lengths being $887 \mathrm{~m}, 416 \mathrm{~m}$, and $216 \mathrm{~m}$, respectively (Fig. 1).

The observation of surface deformation was performed from October 2012 to September 2013. Based on the observed data, the accumulated subsidence at the monitoring stations on the three survey lines were derived (see Fig. 8).

As can be seen from Fig. 8, as the $\mathrm{T}_{3} 281 \mathrm{~N}$ working face was advanced, the surface subsided with its maximum subsidence being $18 \mathrm{~mm}$. For the NS survey line, the subsidence at the monitoring stations arranged in the direction opposite the advance of the working face was larger than those along the advancing direction. In addition, the mining was found to influence a range within a radius of $120 \mathrm{~m}$, and the maximum subsidence $(18 \mathrm{~mm})$ was observed at point $\mathrm{N}_{20}$. On the EW survey line, the section line of the surface subsidence presents a "W" shape, and the maximum subsidence $(16 \mathrm{~mm})$ was found on both sides of the working face. Moreover, with the advance of the working face, the monitoring stations in the advance direction subsided equally. In addition, the monitoring stations above the working face presented slight differences in the subsidence recorded, with the maximum value being $18 \mathrm{~mm}$.

After mining in the $\mathrm{T}_{3} 281 \mathrm{~N}$ backfill face using the SWBM technique, the maximum subsidence on the surface was found to be $18 \mathrm{~mm}$, which was far smaller than the deformation limit tolerated by most surface buildings. At present, the surface buildings are slightly affected by the coal mining and no obvious cracks were found, and so the buildings can be used normally. These results prove that the SWBM technique can effectively control surface movement and deformation and protect buildings on the ground surface.

\section{Conclusions}

The SWBM technique was used to control the surface subsidence under buildings in Tangshan Mine. This research first introduced the fundamental principle of the SWBM technique and then presented the theory of EMH based on the characteristics of strata movement induced by the SWBM. Afterward, based on the EMH theory, a model was established to predict surface subsidence in the $\mathrm{T}_{3} 281 \mathrm{~N}$ working face and the predicted value was found to be less than the critical value for damaging a building. In the meantime, the compaction behaviour of backfill materials were obtained through an experiment on the compaction properties of backfill materials: a degree of compaction of 0.87 was obtained in the experiment when the stress matched the virgin stress, which indicated that during compaction the backfill materials underwent $13 \%$ deformation. Afterward, the surface subsidence was measured after mining the working face using the SWBM technique: it was found that the maximum subsidence reached $18 \mathrm{~mm}$, which was much less than the maximum value tolerated by buildings at the ground surface. In addition, buildings on the surface were slightly influenced by coal mining and no obvious cracks were found therein. These results validate the postulate by which the SWBM method was deemed to have been effective in controlling surface movement and deformation, and preventing buildings from being damaged.

\section{Acknowledgements}

This research was supported by the Fundamental Research Funds for the Central Universities (2017XKZD13).

\section{Conflicts of Interest}

The authors declare that there are no conflicts of interest regarding the publication of this paper.

\section{References}

1. UNVER B., YASITLI N.E. Modelling of strata movement with a special reference to caving mechanism in thick seam coal mining. International Journal of Coal Geology, 66 (4), 227, 2006.

2. WANG J.A., SHANG X.C., MA H.T. Investigation of catastrophic ground collapse in Xingtai gypsum mines in China. International Journal of Rock Mechanics \& Mining Sciences, 45 (8), 1480, 2008.

3. CUI X.M., GAO Y.G., YUAN D.B. Design and application of underground mine paste backfill technology. Geotechnical \& Geological Engineering, 74 (2), 911, 2014.

4. CAN E., KUSCU S., KARTAL M.E. Effects of mining subsidence on masonry buildings in Zonguldak hard coal region in Turkey. Environmental Earth Sciences, 66 (8), 2503, 2012.

5. LOUPASAKIS C., ANGELITSA V., ROZOS D., SPANOU N. Mining geohazards-land subsidence caused by the dewatering of opencast coal mines: The case study of the Amyntaio coal mine, Florina, Greece. Natural Hazards, 70 (1), 675, 2014.

6. DONG X., KARRECH A., BASARIR H., ELCHALAKANI M., QI C. Analytical solution of energy redistribution in rectangular openings upon in-situ rock mass alteration. International Journal of Rock Mechanics and Mining Sciences, 106, 74, 2018.

7. DONG X., KARRECH A., BASARIR H., ELCHALAKANI M., SEIBI A., Energy Dissipation and Storage in Underground Mining Operations. Rock Mechanics and Rock Engineering, 1, 2018.

8. ZHANG J.X., ZHOU N., HUANG Y.L., ZHANG Q. Impact law of the bulk ratio of backfilling body to 
overlying strata movement in fully mechanized backfilling mining. Journal of Mining Science, 47 (1), 73, 2011.

9. LI M., ZHANG J.X., MIAO X.X. Experimental investigation on compaction properties of solid backfill materials. Mining Technology, 123 (4), 193, 2014.

10. BRAKE S.S., DANNELLY H.K., CONNORS K.A. Controls on the nature and distribution of an alga in coal mine-waste environments and its potential impact on water quality. Environmental Geology, 40 (4-5), 458, 2001.

11. ADIBEE N., OSANLOO M., RAHMANPOUR M. Adverse effects of coal mine waste dumps on the environment and their management. Environmental Earth Sciences, 70 (4), 1581, 2013.

12. JIRINA T., JAN S. Reduction of surface subsidence risk by fly ash exploitation as filling material in deep mining areas. Natural Hazards, 53 (2), 251, 2010.

13. FAN G.W., ZHANG D.S., WANG X.F. Reduction and utilization of coal mine waste rock in China: a case study in Tiefa coalfield. Resources Conservation \& Recycling, 83 (5), 24, 2014.

14. BELEM T., BENZAAZOUA M. Design and application of underground mine paste backfill technology. Geotechnical \& Geological Engineering, 26 (2), 175, 2008.

15. OREJARENA L., FALL M. The use of artificial neural networks to predict the effect of sulphate attack on the strength of cemented paste backfill. Bulletin of Engineering Geology \& the Environment, 69 (4), 659, 2010.

16. PALARSKI J. The experimental and practical results of applying backfill. In: Hassani FP, Scoble MJ, Yu TR (eds). Innovations in mining backfill technology, Balkema. Rotterdam, 33, 1989.

17. XUAN D.Y., XU J.L. Grout injection into bed separation to control surface subsidence during longwall mining under villages: case study of Liudian coal mine, China. Natural Hazards, 73 (2), 883, 2014.

18. XUAN D.Y., XU J.L., WANG B.L., TENG H. Investigation of fill distribution in post-injected longwall overburden with implications for grout take estimation. Engineering Geology, 206, 71, 2016.
19. MIAO X.X., ZHANG J.X., FENG M.M. Waste-filling in fully-mechanized coal mining and its application. Journal of China University of Mining \& Technology, 18 (4), 479, 2008.

20. JUNKER M., WITTHAUS H. Progress in the research and application of coal mining with stowing. International Journal of Mining Science and Technology, 23 (1), 7, 2013.

21. ZHANG J.X., JIANG H.Q., DENG X.J., JU F. Prediction of the height of the water-conducting zone above the mined panel in solid backfill mining. Mine Water \& the Environment, 33 (4), 317, 2014.

22. JU F., ZHANG J.X., ZHANG Q. Vertical transportation system of solid material for backfilling coal mining technology. International Journal of Mining Science and Technology, 22 (1), 41, 2012.

23. GUO G.L., ZHU X.J., ZHA J.F., WANG Q. Subsidence prediction method based on equivalent mining height theory for solid backfilling mining. Transactions of Nonferrous Metals Society of China, 24 (10), 3302, 2014.

24. LI M., ZHANG J.X., MIAO X.X., HUANG Y.L. Strata movement under compaction of solid backfill body. Journal of China University of Mining \& Technology, 43 (6), 969, 2014.

25. Coal Industry Bureau of China. Coal mining regulations and coal pillar design affected by buildings, water bodies, railways and main roadway. China Coal Industry Publishing House, Beijing, China, 2000.

26. ZHANG J., ZHANG Q., SUN Q., GAO R., GERMAIN D., ABRO S. Surface subsidence control theory and application to backfill coal mining technology. Environmental Earth Sciences, 74 (2), 1439, 2015.

27. ZHANG J., SUN Q., FOURIE A., JU F., DONG X. Risk assessment and prevention of surface subsidence in deep multiple coal seam mining under dense aboveground buildings: Case study. Human and Ecological Risk Assessment: An International Journal, 2018, doi: 10.1080/10807039.2018.1471579.

28. LIU B.C., LIAO G.H. Surface movements in coal mines. China Industry Publishing House, Beijing, China, 1965.

29. LITWINISZYN J. Statistical methods in the mechanics of granular bodies. Rheologica Acta, 1 (2-3), 146, 1958. 